\title{
Utilizando a criptografia para despertar o interesse e motivar uma aprendizagem significativa no ensino de funções
}

\author{
Making use of cryptography to arouse interest and motivate meaningful \\ learning in mathematical functions teaching
}

\author{
Valdemar Danilo de Carvalho \\ Universidade Federal de São Carlos \\ valddemar10@hotmail.com \\ ORCID:0000-0003-3000-5593
}

\author{
Silvia Maria Simões de Carvalho \\ Universidade Federal de São Carlos \\ silviamsc@ufscar.br \\ ORCID:0000-0001-9519-9339
}

Resumo. Este artigo apresenta uma adaptação de alguns resultados contidos na dissertação de mestrado do primeiro autor, [9]. Uma das maiores dificuldades enfrentadas pelos educadores no ensino de hoje é a falta de interesse dos alunos em conteúdos programáticos da matemática, que muitas vezes é reduzida a um conjunto de técnicas, regras e algoritmos sem nenhuma aplicabilidade ou justificativa. O objetivo deste trabalho é investigar e analisar possíveis contribuições no ensino-aprendizagem de funções tendo como abordagem metodológica a resolução de problemas. O tema criptografia acaba despertando a curiosidade e levando a um processo que possibilita a construção de novos conhecimentos, já que o mesmo é parte integrante do dia a dia dos estudantes. A aplicação de jogos possibilita a construção do conhecimento matemático de forma prazerosa, envolvente e significativa. Pensando nisso, surgiu a ideia de aliar a criptografia a um jogo de caça ao tesouro.

Palavras-chave. Aprendizagem. Funções. Criptografia. Ensino.

Abstract. This article is an adaptation of some results presented in the master's thesis of the first author, [9]. One of the biggest difficulties faced by teachers, nowadays, is the lack of interest from students in math's programmatic contentes, wich, plenty of times, is reduced to a set of techniques, rules and algorithms without applicability or justification. The objective of this manuscript is to investigate and analyze possible contributions in the teaching-learning of functions using the methodological approach to problem solving. 
The cryptography theme ends up arousing curiosity and leading to a process that makes it possible to build new knowledge, since it is an integral part of students' daily lives. The application of games enables the construction of mathematical knowledge in a pleasant, engaging and meaningful way. Thinking about it, the idea arose to combine cryptography with a game of treasure hunting.

Keywords. Learning. Mathematical Functions. Cryptoghaphy. Teaching.

Mathematics Subject Classification (MSC): primary 97D40; secondary 97F60.

\section{Introdução}

Em uma sociedade em constante crescimento e evolução, o conhecimento é uma característica imprescindível para os cidadãos do século XXI, já que ele é ferramenta para trabalhar, conviver, exercer a cidadania e para cuidar do ambiente em que se vive. Com o uso intensivo do conhecimento, a qualidade da educação passa a ser um diferencial nessa sociedade, as competências e habilidades desenvolvidas na vida escolar serão decisivas na participação do indivíduo em sua sociedade, como um cidadão crítico e capaz.

Com essas prerrogativas, entende-se que é preciso oferecer ao educando a oportunidade de aprender, e para isso é indicado nos documentos educacionais vigentes (Currículo do Estado de São Paulo: Matemática e suas tecnologias, 2011, [8]) que se realize uma atividade prática do conteúdo teórico pretendido com o cotidiano do aluno, buscando mostrar a importância desse conhecimento através de sua aplicabilidade.

Analisando os conteúdos matemáticos vistos pelos alunos do ensino médio um dos mais complexos é o que aborda sobre funções. O processo ensino-aprendizagem desse conteúdo é um desafio para professores e alunos. Criar estratégias de ensino que consigam despertar o interesse e propiciar a aprendizagem com o desenvolvimento de habilidades cognitivas e sócio emocionais é um desafio, uma necessidade e um dever do professor. De forma contextualizada o ensino da matemática integra e relaciona a outros conhecimentos, desenvolve no aluno competências e habilidades essencialmente formadoras ( $\mathrm{PCN}+,[1])$.

Uma das competências essenciais em todas as áreas é a de comunicar, expressar, representar, argumentar, ou seja, as várias formas de linguagens, inclusive leitura e escrita. A costumeira abordagem enciclopédica acaba restringindo o aluno, a mero observador passivo. Para evitar que isso aconteça deve-se garantir no processo de ensino aprendizagem algumas interações como: 
1. Atividades onde os alunos participem e cooperem entre si, devendo se posicionarem em relação a determinados assuntos;

2. Temáticas que relacionem a vivência do aluno com o contexto escolar, antes de sair do seu universo vivencial;

3. Observações que necessitem e desenvolvam a percepção de mundo do individuo e gerem participação e registros relevantes feitas pelos alunos.

Um dos maiores problemas nesse processo de ensino aprendizagem segundo Neri (2013, [5]), é o desinteresse por parte dos alunos durante as aulas, sem o interesse fica difícil desenvolver as competências e habilidades necessárias. O aluno não saber um conteúdo não é o problema, pois é só alguém ensinar, o verdadeiro problema está em não querer aprender. $\mathrm{O}$ professor deve ser um agente motivador no processo ensino-aprendizagem instigando a busca de novos conhecimentos pelo educando, tornar suas aulas um local de prazer e descobertas fazendo com que os estudantes se sintam motivados.

Quando o professor oferece o ensino da matemática de forma dinâmica, atrativa e crítica ele estimula no aluno o desenvolvimento do pensamento crítico, a confiança de seu potencial mental e o raciocínio lógico, senso de investigação e criação, além do hábito de empregar suas competências com autonomia.

\section{Criptografia no ensino}

Com os avanços tecnológicos do século XXI o acesso a tecnologia se tornou mais viável a todas as classes sociais. Hoje em dia a maior parte da população utiliza de alguma maneira recursos de comunicação e transações eletrônicas pela internet ou outros. Mas o que garante a segurança dos dados dessas interações digitais? É a criptografia.

Um assunto importante e que atrai olhares no nosso contexto atual, esse tema vem sendo cada vez mais abordado em sala de aula, pois acredita-se que sua utilização desperta o interesse do estudante, motivando-os a aprender os conteúdos matemáticos e ajudando o professor a driblar dificuldades encontradas ao tentar estimula-los.

Um bom exemplo, é o aplicativo de troca de mensagens muito usado nos dias de hoje o WhatsApp, as mensagens são criptografadas para garantir a confidencialidade de todo o conteúdo trocado entre emissor e receptor (DANTAS, 2016, [2]).

O tema criptografia acaba despertando a curiosidade e levando a um processo que possibilita a construção de novos conhecimentos, já que o mesmo é parte integrante do dia a dia dos estudantes. Logo esse tema pode ser utilizado como motivador eficiente de atividades didáticas que conseguem revisar, exercitar, fixar e aprofundar os conteúdos matemáticos (OLIVEIRA JUNIOR, 2015, [6]). 
Uma outra abordagem é a utilização de jogos em sala de aula, pois esta representa uma atividade lúdica que mexe com o desejo e o interesse do jogador pela própria ação, envolve competição e motiva o aluno a conhecer suas possibilidades e limites. O jogo é uma forma de valorizar o conhecimento prévio do aluno, já que este vai adquirindo autoconfiança, incentivado a questionar e corrigir suas ações, analisar e comparar diferentes pontos de vista, organizar e cuidar dos materiais utilizados (MACHINSKI, 2016, [3]). Deste modo a matemática se torna mais divertida e acessível, tendo a participação do sujeito na construção do próprio saber. Segundo MENEZES e CARVALHO (2010, [4]) o aprendizado só é possível quando se relaciona a realidade e as expectativas dos alunos usufruindo dos diferentes recursos para auxiliar no processo de ensino aprendizagem.

Normalmente em sala de aula temos livros, cadernos e lápis, mas um bom jogo encanta, traz fluidez, barulho, alegria e certa vida ao ambiente.

Quando bem planejados e aplicados os jogos possibilitam a construção do conhecimento matemático de forma prazerosa, envolvente e significativa. Pensando nisso, surgiu a ideia de aliar a criptografia a um jogo de caça ao tesouro.

\section{Metodologia da caça ao tesouro}

Essa atividade foi realizada em uma sala de aula do $3^{\circ}$ ano do Ensino Médio com 23 alunos em uma escola pública da rede estadual de São Paulo. Foi aplicada no decorrer do terceiro bimestre do ano letivo (agosto e setembro) em concordância com o conteúdo previsto no currículo paulista vigente no momento. Essa abordagem foi realizada através da metodologia de ensino aprendizagem através da resolução de problemas.

De acordo com as orientações educacionais complementares aos Parâmetros Curriculares Nacionais (PCN+, [1]) a resolução de problemas deve possibilitar aos alunos mobilizar conhecimentos e desenvolver a capacidade para gerenciar informações que estão a seu alcance. Sendo assim, é necessário que professores compreendam como trabalhar com essa metodologia, com o intuito de desenvolver no aluno a capacidade de resolver situações desafiadoras, interagir com os colegas, desenvolver o senso crítico, a comunicação e a criatividade.

Com o intuito de otimizar o processo, a atividade foi dividida em três partes como apresentadas a seguir:

\section{Parte 1 - Duração: 1h30min}

Iniciou-se a atividade com um breve relato histórico, exibindo a evolução e contribuição da criptografia para a humanidade, para isso utilizou-se slides com imagens e frases 
para chamar a atenção com simulação dos métodos de criptografia. Depois dessa parte histórica realizou-se uma atividade introdutória, onde os alunos foram separados em grupos de 4 a 5 pessoas e decodificaram uma mesma mensagem criptografada com o auxilio do professor.

Após a decodificação da mensagem pelos grupos foi realizada uma discussão com o intuito de gerar algumas reflexões e guiar os alunos no propósito da atividade, que é o estudo de funções. Em forma de conversa com toda a sala discutiu-se os pontos mais importantes e as características mais relevantes da função em questão. Nessa discussão o objetivo foi instigar o aluno a dar sua opinião e construir o conceito teórico, valorizando o conhecimento prévio destes.

\section{Parte 2 - O caça tesouro - Duração: 1h40min}

Realizou-se um caça tesouro, onde as dicas estavam escondidas nas repartições da escola. Os alunos da sala foram separados em 5 grupos (de 4 a 5 pessoas) cada um com uma cor, tiveram que decodificar as mensagens com as dicas em cada envelope de cores correspondentes a do seu grupo, todos passando pelos mesmos locais com as mesmas dicas e chaves, mas em ordens diferentes para evitar a copia entre os grupos. Utilizouse funções variadas como chaves e com suas respectivas inversas para decodificarem as pistas.

A chegada foi no mesmo local para todos, nesse local havia um pacote com algumas guloseimas, uma para cada grupo para que todos fossem premiados pelo esforço e se sentissem motivados a ir até o final. Antes do início do caça tesouro foram dadas algumas instruções: Vocês vão iniciar uma caça ao tesouro pela escola, para conseguir alcançar seu objetivo trabalhe em grupo e seja rápido ou alguém pode pegar seu tesouro. Siga as pistas, vocês terão que decodificá-las, para isso utilize o alfabeto com a posição das letras como suas numerações correspondentes, exemplo: $\mathrm{A}=1$, pois ocupa a primeira posição. Escreva a mensagem descriptografada em cada envelope correspondente e entregue todos ao final para retirar seu tesouro. Use seus conhecimentos e construa seu caminho, boa sorte.

O envelope 1 foi distribuído na sala, ele determinou a sequência que cada grupo seguiu já que os caminhos foram diferentes, mas passaram pelos mesmos pontos.

Os outros envelopes foram distribuídos pela escola previamente conforme a organização apresentada no Quadro 1. Nela estão as cores e os números de cada envelope que estavam em cada sala. Essa logística é importante para que todos os grupos passem pelos mesmos lugares em ordens diferentes e consigam chegar ao lugar do tesouro. 


\begin{tabular}{|c|c|c|c|c|c|}
\hline Localização $\quad$ Cor & Amarelo & Verde & Vermelho & Azul & Laranja \\
\hline Início & 1 & 1 & 1 & 1 & 1 \\
\hline Sala 1 & 3 & 2 & 4 & 5 & 2 \\
\hline Biblioteca & 5 & 4 & 2 & 4 & 5 \\
\hline Secretaria & 2 & 3 & 3 & 3 & 4 \\
\hline Sala de computação & 4 & 5 & 5 & 2 & 3 \\
\hline
\end{tabular}

Quadro 1: Distribuição dos envelopes

Em cada envelope foi colocada a chave de codificação e a mensagem codificada (código) correspondente conforme distribuição apresentada no Quadro 1, assim como mostra a Figura 1.

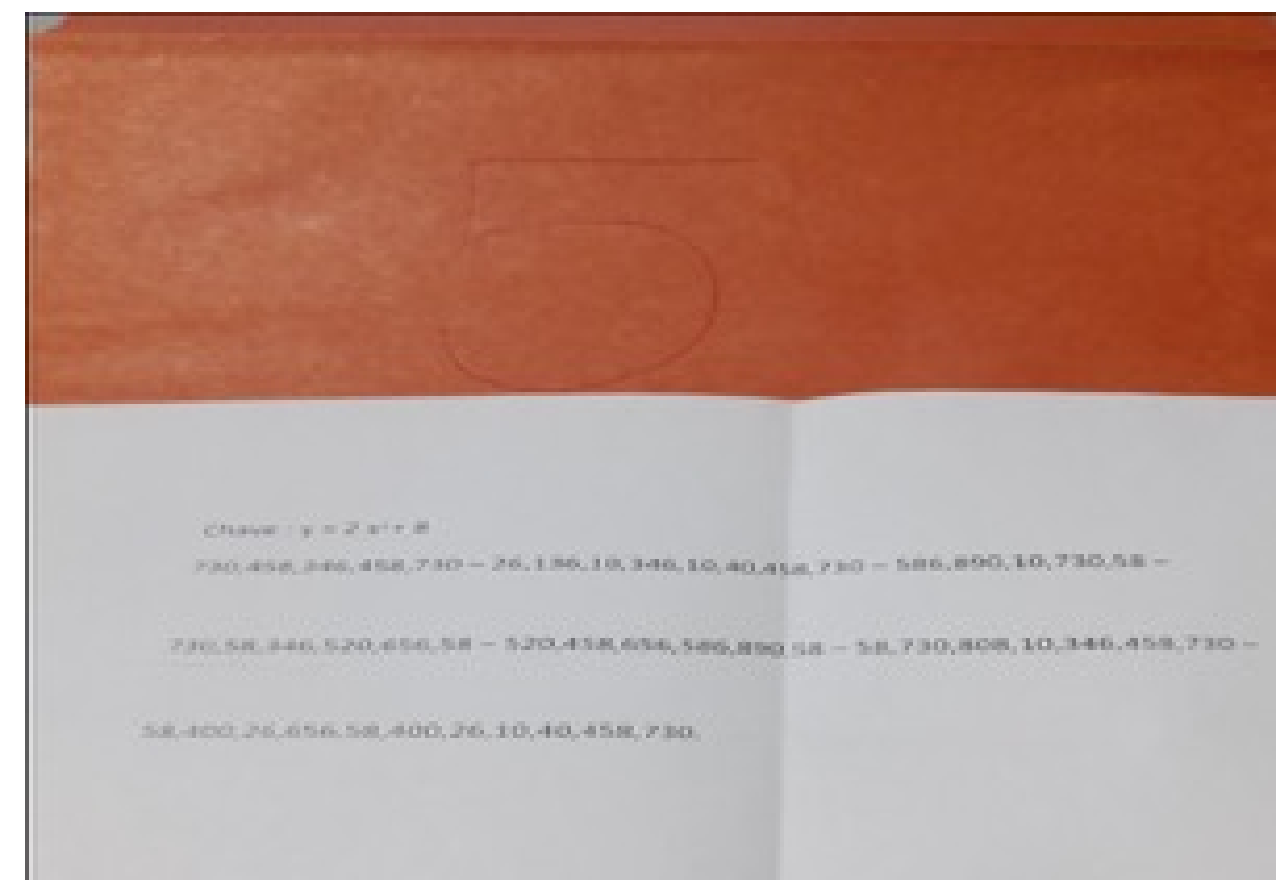

Figura 1: Exemplo de disposição da chave e do código no envelope

A seguir são apresentadas as sequências das pistas utilizadas nos envelopes, separadas por cor para cada grupo. 


\section{Grupo verde}

1 - A sala onde iniciamos nossa caminhada juntos.

Resposta: sala 1 .

Chave: $y=10^{X}$

$10^{1}-10^{19}, 10^{1}, 10^{12}, 10^{1}-10^{15}, 10^{14}, 10^{4}, 10^{5}-10^{9}, 10^{14}, 10^{9}, 10^{3}, 10^{9}, 10^{1}, 10^{13}$, $10^{15}, 10^{19}-10^{14}, 10^{15}, 10^{19}, 10^{19}, 10^{1}-10^{3}, 10^{1}, 10^{13}, 10^{9}, 10^{14}, 10^{8}, 10^{1}, 10^{4}, 10^{1}-$ $10^{10}, 10^{21}, 10^{14}, 10^{20}, 10^{15}, 10^{19}$.

2 - Funciona a parte administrativa da escola, e você retira e entrega documentos no balcão.

Resposta: secretaria.

Chave: $y=2 x+3$

$15,45,31,9,21,33,31,5-5-35,5,39,43,13-5,11,29,21,31,21,41,43,39,5,43$, $21,47,33-11,5-13,41,9,33,27,5-13-47,33,9,13-39,13,43,21,39,5-13-$ $13,31,43,39,13,17,5-11,33,9,45,29,13,31,43,33,41-31,33-7,5,27,9,5,33$.

3 - Onde se pode viajar com sua imaginação sem sair do lugar.

Resposta: biblioteca.

Chave: $y=2^{X}$

$32768,16384,16,32-524288,32-65536,32768,16,32-4194304,512,2,1024,2$, 262144-8, 32768, 8192-524288, 2097152, 2-512, 8192, 2, 128, 512, 16384, 2, 8, 2, 32768 - 524288, 32, 8192 - 524288, 2, 512, 262144 - 16, 32768 - 4096, 2097152, $128,2,262144$.

4 - Estou entre a cinco e a oito, quase sempre trancada.

Resposta: sala de computação

Chave: $y=x^{3}-2$

$123,6857,7998,3373,9259-123,2742,7998,5830,123-(-1)-25,727,2742,25$, 3373-123-(-1)-3373, 727, 7998, 3373-4911, 9259, (-1), 6857, 123-6857, 123, $2195,4094,5830,123-7998,5830,(-1), 2742,25,(-1), 62,(-1)$.

5 - Somos chamados, quase sempre porque estamos encrencados.

Resposta: diretoria

Chave : $y=2 x^{2}+8$ 
$730,458,346,458,730-26,136,10,346,10,40,458,730-586,890,10,730,58-$ $730,58,346,520,656,58-520,458,656,586,890,58-58,730,808,10,346,458$, $730-58,400,26,656,58,400,26,10,40,458,730$.

Os outros envelopes tinham as mesmas chaves e mensagens criptografadas, conforme a distribuição abaixo:

Grupo amarelo

1. Funciona a parte administrativa da escola, e você retira e entrega documentos no balcão. (secretaria)

2. A sala onde iniciamos nossa caminhada juntos. (sala 1)

3. Estou entre a cinco e a oito, quase sempre trancada. (sala de computação)

4. Onde se pode viajar com sua imaginação sem sair do lugar. (biblioteca)

5. Somos chamados, quase sempre porque estamos encrencados. (diretoria)

Grupo vermelho

1. Onde se pode viajar com sua imaginação sem sair do lugar. (biblioteca)

2. Funciona a parte administrativa da escola, e você retira e entrega documentos no balcão. (secretaria)

3. A sala onde iniciamos nossa caminhada juntos. (sala 1)

4. Estou entre a cinco e a oito, quase sempre trancada. (sala de computação)

5. Somos chamados, quase sempre porque estamos encrencados. (diretoria)

\section{Grupo azul}

1. Estou entre a cinco e a oito, quase sempre trancada. (sala de computação)

2. Funciona a parte administrativa da escola, e você retira e entrega documentos no balcão. (secretaria)

3. Onde se pode viajar com sua imaginação sem sair do lugar. (biblioteca)

4. A sala onde iniciamos nossa caminhada juntos. (sala 1) 
5. Somos chamados, quase sempre porque estamos encrencados. (diretoria)

Grupo laranja

1. A sala onde iniciamos nossa caminhada juntos. (sala 1)

2. Estou entre a cinco e a oito, quase sempre trancada. (sala de computação)

3. Funciona a parte administrativa da escola, e você retira e entrega documentos no balcão. (secretaria)

4. Onde se pode viajar com sua imaginação sem sair do lugar. (biblioteca)

5. Somos chamados, quase sempre porque estamos encrencados. (diretoria)

Na secretaria os envelopes estavam guardados com a agente de organização que entregava os envelopes conforme solicitado. No ponto final (diretoria) a vice-diretora ficou na sala e escondeu os tesouros um a um, assim os grupos tiveram que procurar na diretoria. Lembrando que as pistas foram feitas para essa turma, em outras turmas as pistas devem ser reformuladas de modo apropriado ao contexto desses alunos.

\section{Parte 3 - Duração: 45min.}

$\mathrm{Na}$ aula após a realização do caça tesouro, foram exploradas as funções utilizadas como chaves na decodificação das pistas, com o auxilio de um aplicativo de celular (Geogebra) foi solicitado aos alunos que construíssem os gráficos e discutido em conjunto com a sala suas principais características. Explanamos o domínio e imagem e a relação entre esses conjuntos nas funções e suas inversas.

Após essa discussão os alunos responderam ao questionário para diagnosticar o resultado da atividade na aprendizagem e no interesse dos alunos.

\section{Resultados e discussões}

No início da primeira atividade quando foi apresentado um breve resumo de algumas cifras consideradas importantes na história da humanidade, os alunos demonstraram grande interesse no assunto criptografia e, chegaram a relacionar algumas das cifras mostradas com jogos conhecidos na internet.

A curiosidade em descobrir o que estava escrito na mensagem motivou os alunos a se esforçarem para decodificar. Diferente dos exercícios simples de resolução de funções, 
nessa atividade os alunos tinham um propósito mais claro, descobrir o conteúdo do texto. Esse propósito os motivou no processo para a realização dos cálculos necessários.

Durante a aplicação da terceira parte da metodologia abordada, em resposta ao questionário os alunos se mostraram mais interessados e com observações pertinentes, diferentemente do que ocorre em aulas tradicionais (expositivas). Essa motivação durante o processo facilitou a construção dos conceitos teóricos após a realização dessa atividade.

Para a aplicação do caça tesouro primeiro os alunos foram separados em 5 grupos de 4 a 5 pessoas, para alcançar o objetivo da aprendizagem proposta, escolheu-se como capitães os melhores alunos da sala e eles foram escolhendo seus times, integrante por integrante seguindo uma ordem de sorteio, assim os grupos tinham afinidade para discutir estratégias e seus integrantes tinham diferentes níveis de aprendizagem possibilitando que ajudassem um ao outro. Essa separação foi escolhida, pois a sala em questão tem uma relação de amizade muito homogênea, e já estão acostumados a este tipo de agrupamento nas atividades.

Para acelerar e ajudar no processo de cálculo foi disponibilizado para cada grupo uma calculadora convencional, já que tínhamos números bem grandes envolvidos o que poderia atrasar a realização da tarefa.

Os alunos se mostraram muito animados antes, durante e depois da atividade. Também foi observado que a inclusão de uma atividade não rotineira despertou grande interesse dos alunos que estavam empenhados em realizar os cálculos e descobrir a mensagem cifrada.

Eles se organizaram e dividiram tarefas dentro dos grupos, construíram tabelas para organizar e facilitar a decodificação como mostrado na Figura 2.

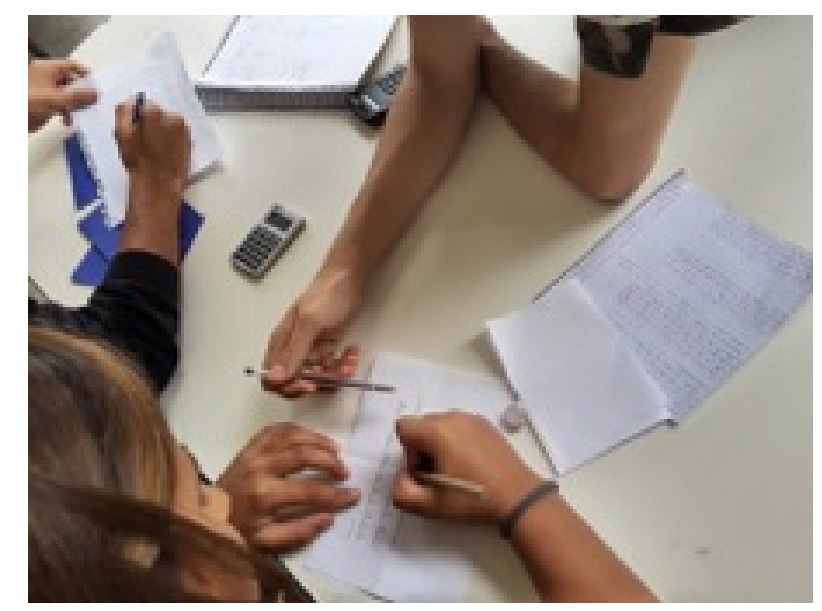

Figura 2: Organização dos alunos na decodificação 
Alguns alunos acharam que as calculadoras iriam facilitar e muito a decodificação, mas durante o processo perceberam que a calculadora só auxiliava nos cálculos básicos e que os processos que eram mais difíceis precisavam de raciocínio.

A interação dos componentes em cada grupo auxiliou os alunos com mais dificuldade no processo de aprendizagem. Para poder ajudar seu grupo eles precisavam saber como resolver os cálculos e quanto mais pessoas ajudando mais rápido conseguiam decifrar as pistas. Assim os dois lados do processo tinham um interesse em comum, motivando-os a se ajudarem e superando suas dificuldades individuais e em grupo.

No final todos os grupos conseguiram chegar ao tesouro que estava localizado na diretoria. Cada grupo ao seu tempo, cada um de uma vez. Eu observei a chegada na diretoria. Quando encontravam, agradeciam e saiam para dividir as guloseimas com uma expressão de realização e satisfação estampadas no rosto.

Durante a discussão e estudo das funções utilizadas como chaves pode-se notar que os alunos estavam interessados e relacionaram as características dos gráficos com as propriedades das funções com mais facilidade e entusiasmo na discussão, se sentiram mais pertencentes ao processo de construção e não meros ouvintes.

O Gráfico 1 mostra a resposta dos alunos ao questionário aplicado após a atividade do caça tesouro, observando podemos notar que a atividade proposta despertou o interesse dos alunos, estimulando-os no processo de ensino aprendizagem.

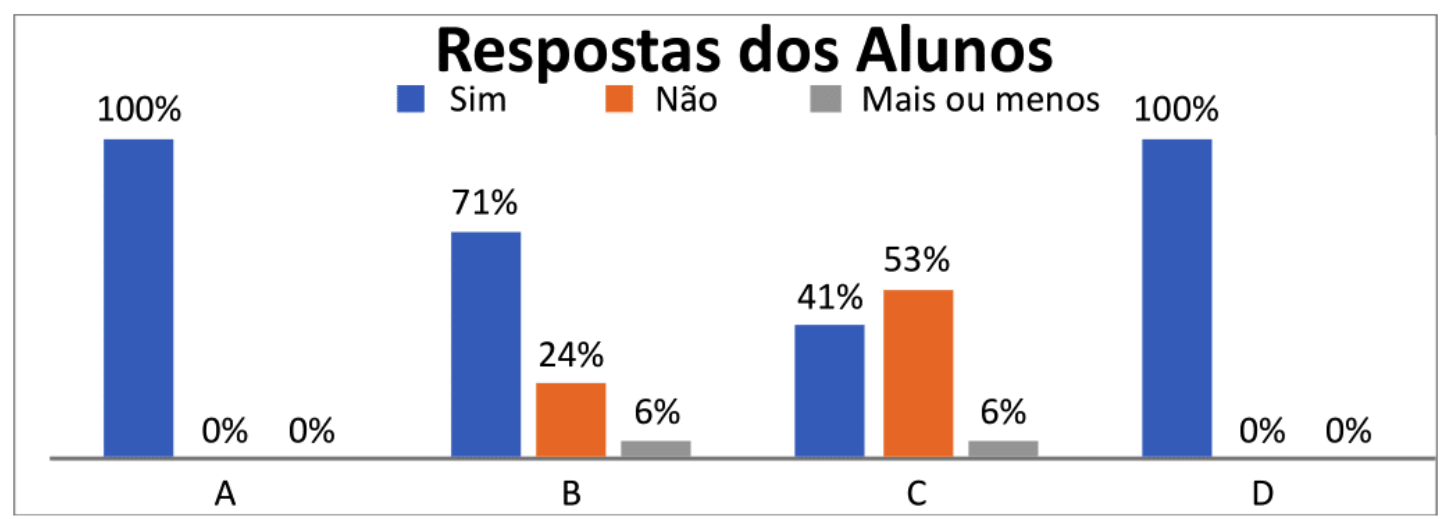

Gráfico 1: Respostas do Questionário

Na Tabela 1 são apresentadas algumas respostas dadas pelos alunos no item "a" do questionário (A atividade proposta despertou o interesse em participar, estimulando seu aprendizado? Por quê?). 


\begin{tabular}{|c|c|}
\hline Aluno & Respostas(Porquês) \\
\hline A & $\begin{array}{l}\text { Porque é uma atividade que sai da rotina e mostra o trabalho } \\
\text { entre amigos. }\end{array}$ \\
\hline $\mathrm{B}$ & Porque tinha prêmio KKK, e fez com que a gente se divertisse. \\
\hline $\mathrm{C}$ & $\begin{array}{l}\text { Porque é uma coisa diferente, você estava na matéria mais } \\
\text { mesmo assim ajudou a sair da rotina. }\end{array}$ \\
\hline $\mathrm{D}$ & $\begin{array}{l}\text { Porque foi uma atividade muito dinâmica e atrativa, além de } \\
\text { despertar o interesse de competição, o que estimulou ainda } \\
\text { mais, colocou em prática nossos conhecimentos. }\end{array}$ \\
\hline $\mathrm{E}$ & Porque foi uma atividade diferente do nosso dia a dia escolar. \\
\hline $\mathrm{F}$ & Porque sai da rotina e da menos preguiça. \\
\hline $\mathrm{G}$ & $\begin{array}{l}\text { Pois foi um método diferente e divertido de realizar os exercí- } \\
\text { cios. }\end{array}$ \\
\hline $\mathrm{H}$ & $\begin{array}{l}\text { Por ser algo diferente das aulas convencionais, o que chama } \\
\text { mais atenção. }\end{array}$ \\
\hline I & $\begin{array}{l}\text { Pois foi uma atividade que necessitava de todos para ajudar pois } \\
\text { cada um tinha seu papel no grupo. }\end{array}$ \\
\hline $\mathrm{J}$ & $\begin{array}{l}\text { Porque você fica curioso em saber o que está escrito, e também } \\
\text { é uma novidade. }\end{array}$ \\
\hline
\end{tabular}

Tabela 1: Algumas respostas dos alunos ao item "a" do questionário aplicado.

Conforme o Gráfico 1, todos alunos acharam que a atividade despertou o interesse em participar, estimulando seu aprendizado. No Quadro 1 os alunos explicam porque eles tiveram essa opinião. Eles acharam a atividade diferente e divertida, tirando-os da rotina da sala de aula. Um ponto importante apontado por eles foi a interação entre os membros do grupo. A curiosidade dos alunos em saber quais eram as pistas e quais eram os doces também ajudou a despertar o interesse em participar da atividade. A atividade atingiu os objetivos segundo POLYA (1978, [7]), pois o caça ao tesouro instigou a curiosidade e criatividade dos alunos, tirando-os de meros espectadores para agentes ativos da aprendizagem.

Na Tabela 2 são apresentadas algumas respostas dadas pelos alunos no item "d' do questionário (Você acha que essa atividade facilitou sua aprendizagem dos conceitos de funções em relação às aulas mais tradicionais com lousa e giz, com resolução de exercícios teóricos? Por quê?). 


$\begin{array}{cl}\text { Aluno } & \begin{array}{l}\text { Respostas(Porquês) } \\ \text { A }\end{array} \\ \text { B } & \begin{array}{l}\text { Porque é uma forma diferente e menos enjoativa e cansativa. } \\ \text { Porque no mesmo tempo que você está aprendendo, também } \\ \text { Cstá se divertindo. }\end{array} \\ \text { D } & \begin{array}{l}\text { Pois ao sair do ritmo de ficar só sentado e copiando, tudo fica } \\ \text { melhor. }\end{array} \\ \text { E } & \begin{array}{l}\text { Porque ali você sente vontade de fazer para continuar a brinca- } \\ \text { deira. }\end{array} \\ \text { F } & \begin{array}{l}\text { Porque houve uma interação maior entre os colegas e por ser } \\ \text { dinâmica estimulou muito. }\end{array} \\ \text { G } & \begin{array}{l}\text { Porque é mais interessante ao aluno. } \\ \text { Pois por conta do incentivo, o esforço e o interesse é maior. }\end{array} \\ \text { H } & \begin{array}{l}\text { Pois foi algo que estimulou a mente e exigiu participação de } \\ \text { todos. } \\ \text { I }\end{array} \\ \text { Porque você fica mais empenhado e tem a ajuda do grupo para } \\ \text { resolver as funções. }\end{array}$

Tabela 2: Algumas respostas dos alunos ao item "d" do questionário aplicado.

Conforme mostra o Gráfico 1, 100\% dos alunos acharam que a atividade facilitou a aprendizagem. Ao analisarmos as repostas no Quadro 2 verificamos que os alunos apresentaram essa maior facilidade por causa do interesse e da vontade deles mesmos em realisar o que foi proposto.

Na Figura 3 e na Figura 4 são mostradas outras respostas dos alunos em perguntas do questionário. Nestas respostas notamos a importância de despertar o interesse do aluno para as atividades a serem realisadas. É esse interesse que possibilita e facilita o aprendizado por parte do aluno. Notamos ainda que os alunos tem consciência de que o aprendizado deles depende de seu interesse nas atividades propostas.

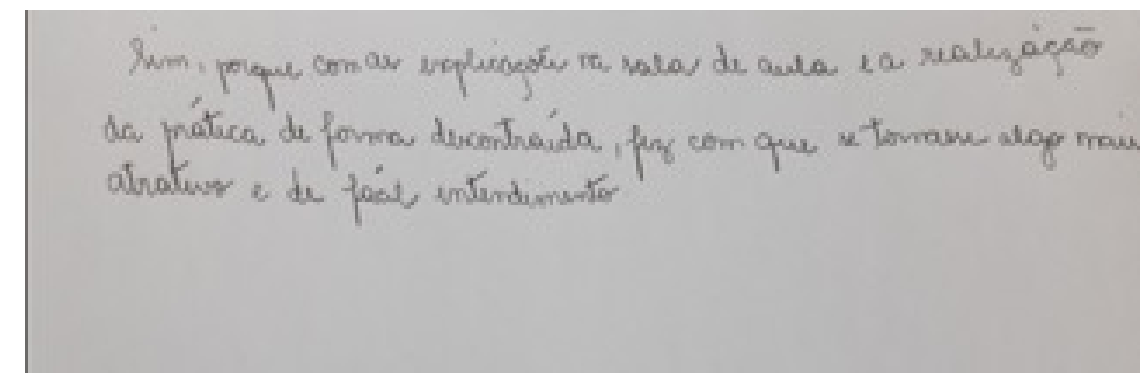

Figura 3: Resposta do aluno Y 


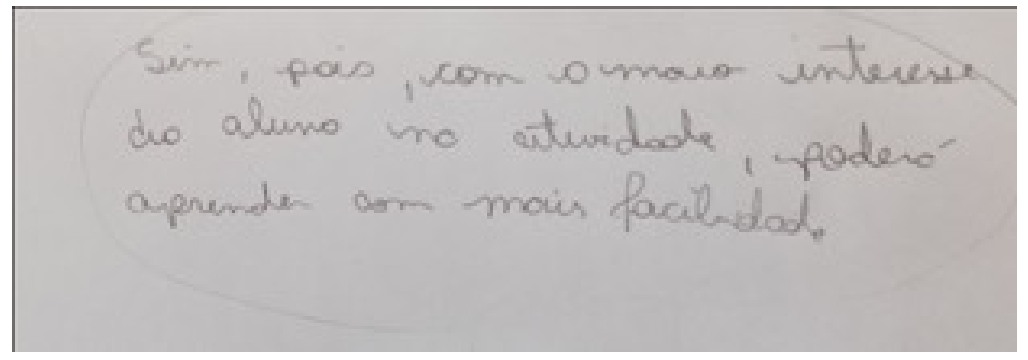

Figura 4: Resposta do aluno X

Após a aplicação da atividade os alunos apresentaram uma melhora considerável nos resultados das avaliações escritas às quais foram submetidos. Em sua maioria os alunos aumentaram suas notas nas avaliações de mesmo conteúdo programático depois da aplicação do caça tesouro em relação às avaliações anteriores.

Somente $8,7 \%$ dos alunos apresentaram uma queda de rendimento em nota nas avaliações escritas analisadas. Os outros $91,3 \%$ dos alunos apresentaram melhora ou mantiveram seu rendimento.

\section{Conclusão}

Nesse trabalho foi apresentado e testado uma atividade didática para o ensino de funções tendo como tema de abordagem a criptografia. Verificou-se que a atividade proposta atingiu seu objetivo de despertar e estimular o interesse dos alunos melhorando assim seu desempenho na atividade escrita.

A análise dos resultados nos mostra um aumento significativo no desempenho dos alunos na atividade escrita após a aplicação do caça tesouro.

Assim o caça tesouro com a temática criptografia, une duas coisas que devem ser asseguradas aos alunos durante as aulas: atividade prática e contextualização com o cotidiano do aluno, se mostrando eficaz na construção do conhecimento significativo e de um cidadão pleno.

Ao utilizar a essa metodologia, o papel do professor muda de "comunicador de conhecimento" para o de observador, organizador, consultor, mediador, controlador e incentivador da aprendizagem. Com base no que foi apresentado nesse artigo notou-se a importância do professor desenvolver atividades práticas com seus alunos como jogos e brincadeiras bem planejadas e estruturadas em prol de um objetivo pré-determinado.

O caça tesouro aplicado se mostrou eficaz na árdua tarefa diária do professor de despertar o interesse dos alunos e atrair sua atenção, além de estimular os estudantes a se esforçarem durante o processo de ensino aprendizagem. 


\section{Referências}

[1] BRASIL, Secretaria de Educação Média e Tecnológica. PCN+: Ensino Médio Orientações educacionais complementares aos parâmetros curriculares nacionais. Brasília: MEC, 2002. 141p.

[2] DANTAS, Andréa de Araujo. A Criptografia no Ensino Fundamental e Médio. Monografia (especialização), Universidade Federal do Rio Grande do Norte, Caicó - RN, 2016.

[3] MACHINSKI, Alessandra e TROBIA, José. Utilizando jogos como estratégia para o ensino e aprendizagem da matemática. Cadernos PDE, secretaria de educação do Paraná, Volume 1, Paraná, 2016.

[4] MENEZES, Luiza de Abreu. CARVALHO, Marcos Pavani. Criptografia na sala de aula, X Encontro Nacional de Educação Matemática, Salvador, 2010.

[5] NERI, M. Motivos da evasão escolar. [S.1.], 2013. Disponível em: https://www.cps.fgv.br/ibrecps/rede/finais/Etapa3-Pesq_ MotivacoesEscolares_sumario_principal_anexo-Andre_FIM. pdf Acesso em: 28/02/2020.

[6] OLIVEIRA JUNIOR, Gilmar Rezende de. Algumas aplicações da criptografia no ensino fundamental. Universidade Federal do Tocantins, Dissertação (Mestrado Profissional), Palmas- TO, 2015.

[7] POLYA, G. A. A arte de Resolver Problemas. Tradução: Heitor Lisboa de Araújo. Rio de Janeiro, Interciência, 1978.

[8] SÃO PAUlO, (Estado) Secretaria da Educação. Currículo do Estado de São Paulo: Matemática e suas tecnologias / Secretaria da Educação; coordenação geral, Maria Inês Fini; coordenação de área, Nilson José Machado. ? 1. ed. atual. ? São Paulo: SE, 2011.

[9] VALDEMAR, D. C. Uma metodologia com uso de criptografia pra ensino de funções. 2020. Dissertação (Mestrado em Ensino de Matemática) - Departamento de Matemática, Universidade Federal de São Carlos, Sorocaba, 2020.

口

Submetido em 25 jul. 2020

Aceito em 17 out. 2020 